\title{
Reformation and Innovation of Practical Teaching for the Applied Undergraduate
}

\author{
Hongwang Zhao \\ Guilin University of Aerospace Technology, Guilin 541004, china \\ zhw3721@qq.com
}

Keywords: practical teaching, automobile specialty, applied undergraduate.

\begin{abstract}
Practical teaching is an important teaching link in engineering colleges, especially applied engineering colleges, it plays an irreplaceable role in cultivating students' innovative consciousness, creative spirit and creative ability. In order to improve students' engineering practice and design innovation ability, this paper proposes some reform and the futur work ideas in practice. The construction of experimental course system, experimental teaching management system and operation mechanism are studied and explored, it shows that the train of thought has strong reference significance for automobile or other engineering majors.
\end{abstract}

\section{Introduction}

Automobile specialty is a practical and applied discipline, the knowledge and techniques involved include materials, machinery, electronics, computers, communications, remote sensing, aesthetics, and so on. The employment prospects of the automotive profession are vast, graduates mainly work in automobile design, manufacture and test departments, and they can also engage in automobile sales, automobile service and auto maintenance work.

According to the graduate recruitment situation of automobile enterprises in recent years, enterprises not only pay attention to students' course evaluation results, but also pay more attention to students' practical experience and ability.This year's graduates lack general practice experience, and students with strong practical ability will become the leader of job hunting, which puts forward higher requirements for the practice teaching system and teaching quality of automobile major.Many universities, which after undergraduate teaching evaluation and professional evaluation, have carried out radical reform, exploration and practice of the practical teaching system in the talent training $\operatorname{program}^{[1]}$. Under the two driving forces of the changing demand for automotive talents and the reform and development of higher education,The automobile specialty of Guilin University of Aerospace Technology has made a useful exploration and practice of the practical teaching system.

\section{Design Thought and Construction of Practice Teaching System}

The training objective of automotive major is to have highly qualified application and technical personnel with strong basic knowledge of mechanical engineering and broad knowledge of automotive engineering ${ }^{[2]}$. The main courses include theoretical mechanics, material mechanics, electrical engineering, electronic technology, mechanical principle, mechanical design, automobile construction, automobile theory, automobile design, automobile test science, automobile manufacturing technology, etc.

According to the practical characteristics of auto industry from the technical characteristics and the needs of talents to cultivate industry oriented, reasonable knowledge structure, strong practical ability of application talents as the goal,we have done the automotive specialty practice teaching reform. The guiding ideology of the reform of practice teaching is the combination of inside and outside class, the students basic ability, innovation ability, the ability of engineering practice, to explore the potential of students; follow the laws of cognition, practice teaching in the experimental course, curriculum design, professional practice and social equal steps, effective to cultivate students' practical ability and consolidate the students; the theory of knowledge, clarify the curriculum should 
have the practical ability, according to the different levels of basic skills, comprehensive skills and innovation ability, and gradually improve the practice ability of students.

According to the design idea of the practical teaching system, the practice teaching system is subdivided into four sub-systems: the practical teaching target system, the practical teaching content system, the practice teaching condition system and the practice teaching management system,as shown in fig.1.

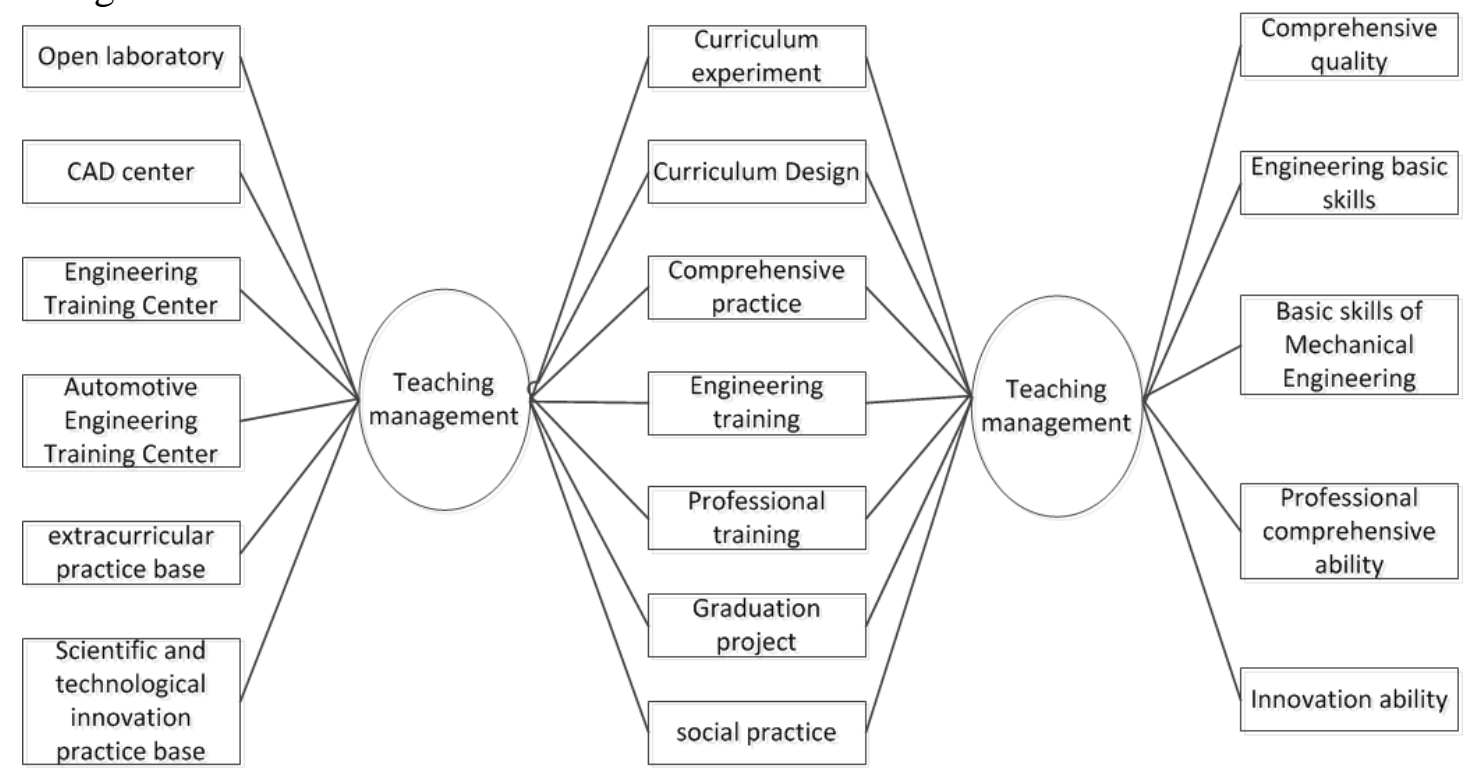

Fig. 1 Construction of practical teaching system

\section{Construction of Experimental Teaching Management System and Operation Mechanism}

It is an important guarantee for improving the quality of experiment teaching to set up the management system and operation mechanism of automobile specialized experiment teaching with its own characteristics ${ }^{[3]}$. On the basis of drawing on the advanced experience of domestic and overseas experimental teaching, we have actively explored and implemented the operating mechanism of experimental teaching.

\subsection{Strengthening the construction of experimental teaching team.}

The practical ability and level of the experimental teacher is one of the key factors that determine the students' practical innovation ability.In order to comprehensively improve the quality of experimental teachers, our school professional car through external introduction and internal training, the construction of a reasonable structure, stable staff, not only understand the theory and understand the professional operation, strong practical ability and good teaching effect of the "double" experimental teachers team.

\subsection{Highlighting the Openness of Experimental Teaching.}

Open laboratory is an important part of innovative education, an open laboratory to the greatest extent possible to attract students to explore, and provide a vast space to play for their creativity and initiative. Our professional car in the open experimental teaching carried out active exploration, through the reasonable arrangement of the opening hours of the laboratory, make full use of the limited laboratory resources, improve the use rate of equipment; through scientific arrangement of experimental project, do the continuity of experimental contents, and to facilitate the centralized management of equipment and maintenance.

\subsection{Attach Importance to Computer Aided Experimental Teaching Methods.}

The computer multimedia technology and the simulation technology have the image, the direct viewing characteristic, uses it in the experimental teaching process, is expands the student experiment skill training the important way. Our professional car in the process of experimental teaching, attaches great importance to using computer assisted instruction means, such as by computer assisted instruction experiment principle demonstration and experiment instrument operation training for the 
students, the students are familiar with the equipment greatly shorten the time, and effectively reduces the loss and the cost of experiment.

\subsection{Improve the Experimental Teaching Management System and Evaluation System.}

In the process of reform and practice of experimental teaching system, the automobile major in our school has further standardized the experimental teaching management system and teaching effect evaluation system, and fully mobilized the enthusiasm of teachers and students to participate. The main measures adopted are as follows :(1) make full use of campus network resources. All experiments all access, full implementation of the teachers work system, students can make an appointment through the network experiment time. (2)Establish a multi reward mechanism to fully arouse the enthusiasm of teachers and students.

To improve the teaching quality of the teachers to contribute, according to contribution, to give the corresponding "work performance award" in the process of year-end distribution in job performance includes guiding students to participate in science and technology competition, guiding college students innovation project, absorb students attend the teachers' scientific research, for resources outside the school, on the experimental equipment for the two development and to improve the teaching effects and other aspects of content. At the same time, also give more incentives to participate in innovative experimental projects or various science and technology competitions students, such as the priority to support innovative projects, innovative credit incentives, recommend graduate students and special scholarship etc.

\section{Summary}

In order to meet the needs of the cultivation of innovative talents under the new situation, automobile specialty of Guilin University of Aerospace Technology have done experimental teaching system and laboratory construction of reform and exploration, through the optimization of curriculum system configuration, strengthening the experimental facilities and improve the laboratory management system and other measures to create an environment conducive to the new experimental teaching system to cultivate students' innovation consciousness and innovation ability. Through the implementation of these reform measures, fully mobilize and play the enthusiasm of teachers and students, and create a good atmosphere to promote active learning of students, stimulate the students' practice innovation upsurge.

\section{Acknowledgments}

This work is carried out with the support of the research project of teaching reform of Vocational Education in Guangxi in 2016.The construction and practice of the curriculum system of automobile inspection and maintenance specialty based on the cultivation of post professional ability (NO.:GXGZJG2016A058).

\section{References}

[1]. Tang S, Zheng M. Exploration and Practice of the Reform of the Practical Teaching System for Chemical Engineering in Transformation Period [J]. Science Education Article Collects, 2015(12):45-48.

[2]. Tan H, Lei W N, Zhou J Y, et al. The Thoughts and Practice on Construction of The Graduate Student's Teaching Staff of the Professional Degree- - A Case Study of Jiangsu University of Technology[J]. Journal of Jiangsu University of Technology, 2015(05):23-26.

[3]. Han S J, Ji-Ran L I. Exploration of Promoting Quality of Experiment Teaching in high Vocational Colleges by the Construction of the open Laboratory[J]. Times Agricultural Machinery, 2016(03):18-22. 